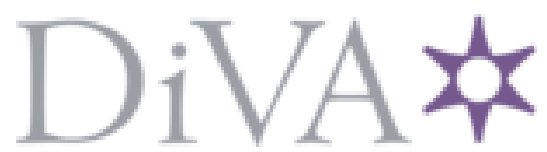

http://www.diva-portal.org

\title{
Postprint
}

This is the accepted version of a paper published in International Journal of Transgenderism. This paper has been peer-reviewed but does not include the final publisher proof-corrections or journal pagination.

Citation for the original published paper (version of record):

Lindroth, M., Zeluf, G., Mannheimer, L N., Deogan, C. (2017)

Sexual health among transgender people in Sweden.

International Journal of Transgenderism, 18(3): 318-327

https://doi.org/10.1080/15532739.2017.1301278

Access to the published version may require subscription.

N.B. When citing this work, cite the original published paper.

Permanent link to this version:

http://urn.kb.se/resolve?urn=urn:nbn:se:hj:diva-35347 


\section{Sexual health among transgender people in Sweden}

Introduction: Transgender people's general health and sexual function has previously been studied. However, holistic sexual health - physical, emotional and relational well-being in relation to sexuality - as both a determinant for and a part of general health is an understudied field in research concerning health among transgender people. There is no research addressing holistic sexual health and sexual health determinants combining quantitative and qualitative data.

Aim: To explore and describe holistic sexual health and sexual health determinants among transgender people in Sweden.

Methods: For the purpose of this paper, descriptive statistics from a previous web-based survey with 796 respondents and quotes from a previous qualitative interview study with 20 transgender people were combined.

Results: Physical, emotional and relational well-being are all vital aspects for experiencing holistic sexual health, i.e. they are all important sexual health determinants, although of different importance to different individuals at different times. Satisfaction with sex life, having an ongoing sexual relationship and having been exposed to disrespectful or discriminatory care are examples of physical, emotional and relational sexual health determinants that are connected to factors such as condom use, access to respectful STI/HIV-testing and having received reimbursement for sex. Experiences of disrespect and discrimination were reported in both the qualitative and the quantitative data, and in the qualitative data a wish for equity in access to sexual health care is evident.

Conclusion: The results provide a broad and extensive insight into transgender people's sexual health in Sweden. Furthermore it underlines that access to non-discriminatory health care 
services is vital, including access to gender-confirming care and different sexual health promoting and preventive services such as testing facilities.

Key words: holistic sexual health, non-binary people, sexual health determinants, sexual wellbeing, transgender people 


\section{Sexual health among transgender people in Sweden}

\section{Introduction}

In this paper, the term transgender is used as a description of individuals whose gender identity or gender expression partly or always differs from the norm of the gender ascribed to them at birth, including individuals who identify as non-binary (not male or female or both). Transgender people and their needs remain not fully understood, not only by health-care providers, but also more generally in society (The Lancet Series, 2016). Regarding sexual health, transgender and gender variant people are a vulnerable population at risk for sexual ill health, as they are continuously exposed to discrimination, stigmatization and legal, economic and social marginalization and exclusion (Adams et al., 2016; Leppel, 2016; World Health Organization, 2015). In Sweden, the national strategy for equal opportunities and rights regardless of sexual orientation, gender identity or gender expression was launched in 2015, with the aim to strengthen efforts to improve the situation of lesbian, gay, bisexual and transgender (LGBT) people (Government Offices of Sweden, 2016). The strategy underlines transgender peoples' rights to equal opportunity and rights in a range of areas of which health and health care, including sexual health and health care, is one of the key strategic foci.

The number of individuals identifying as transgender in Sweden is unknown. Results from a national public health survey show that 0.4 percent identified as transgender, which is in line with previous estimates (Public Health Agency of Sweden, 2015a). Another source of estimation is the incidence and prevalence for legal and surgical sex reassignment in Sweden over a 50-year period (Dhejne et. al., 2014). Between 1960 and 2010, 767 individuals (289 natal females and 478 natal males) applied for legal and surgical sex reassignment. The incidence increased from 0.16 to $0.42 / 100,000 /$ year (Female to Male, FtM) and from 0.23 to 0.73/100,000/year (Male to Female, MtF) with a point prevalence in December 2010 for individuals who applied for a new legal gender at 1:13,120 (FtM) and 1:7,750 (MtF). These 
estimations are however indirect and uncertain since they exclude individuals who, although identify as transgender, may not apply for legal gender change nor medical gender-confirming interventions. Transgender people may face various health concerns that are directly and indirectly related to exposure to prejudice, discrimination and violence (Kattari et al., 2015; Meyer, 2007). Furthermore, transgender people report experiences of health care services being inadequate and insensitive to their needs (Kanamori \& Cornelius-White, 2016; Lombardi, 2001; Roller, Sedlak \& Draucker, 2015), poor mental health and elevated suicide risk (Bauer et al., 2015; Dhejne et al., 2011; Dhejne et al., 2016; Millet et al., 2017), and high prevalence of HIV and other sexually transmitted infections, STIs (Baral et al., 2013; Meyer, 2007).

Sexual health, as a determinant for as well as a part of general health, can be defined as a holistic experience of physical, emotional, mental and social well-being in relation to sexuality, not merely the absence of impairment (World Health Organization, 2015). From this public health perspective holistic sexual health - encompassing physical, emotional and relational well-being - among transgender people is a neglected area in research. It has been argued that although sexual health following gender-confirming medical interventions is important, it is not adequately addressed by professionals specialized in transgender care (Wierckx et al., 2011). Sexual health following medical gender-confirming interventions has previously been examined, using standardized self-report instruments to measure post-operative sexual health as sexual function, i.e. mainly physical aspects (Costantino et al., 2013; Weyers et al., 2009), rather than sexual health as holistic well-being. Studies examining quality of life and health related quality of life among transgender people also exist (Motmans et al., 2012; Pitts et al., 2009). But again, standardized self-report instruments are used, and holistic sexual health (i.e. physical, emotional and relational well-being) is not addressed. Quantitative data alone do not provide a deep understanding of how transgender people experience sexual health in this 
broader sense. Studies that define sexual health as something more than sexual function or satisfaction, and that include the voices of transgender people has not been carried out.

In terms of gender-confirming care, levels of psychopathology and psychiatric disorders among transgender people improve following gender-confirming medical interventions, pointing at the importance of access to care (Dhejne et al., 2016). If and how mental health among transgender people is related to sexual health is unknown, but body dissatisfaction has been described as connected to psychological distress (Bouman, de Vries \& T'Sjoen, 2016). This implies challenges for transgender people who do not have access to the gender-confirmatory medical interventions they want and need. The relational aspect of sexual health is yet another vital component. In a Swedish survey focusing on sexual health among transgender people, a majority of the 237 respondents say that sex with a partner is something positive, and a majority want to have a sexual partner (Gäredal \& Orre, 2011). Summarizing, little is known of holistic sexual health among transgender people, including those who identify as non-binary.

\section{Aim}

The aim of the current paper is to explore and describe sexual health among transgender people in Sweden. Sexual health as an important public health goal is seen both as a determinant for and a part of general health, referring to health in relation to sexuality as a holistic experience of physical, emotional and relational well-being. Within this holistic framework for studying sexual health, the aim is to nuance the description of transgender people's sexual health by combining quantitative data from a survey study with qualitative data from an interview study. In addition, quantitative and qualitative data on three potential sexual health determinants (safer sex, access to testing, and experiences of reimbursement for sex) is presented. 


\section{Methods}

Two studies - one aim

With an explorative and descriptive design, this paper presents the findings from two Swedish studies; a web-based survey and a qualitative interview study. Both studies were conducted during the years 2014-2015 and on behalf of the Public Health Agency of Sweden as part of the work with monitoring and reporting on the health of LGBT people and HIV/STI-prevention. The studies were approved by the Regional Ethical Boards in Stockholm (2014/857) and Lund $(2014 / 587)$.

The web-based survey

An anonymous online survey on general health and determinants of health among transgender people was conducted in 2014 (Public Health Agency of Sweden, 2015; Zeluf et al., 2016). Participants were recruited via advertisements and e-mail invitations on Qruiser, Scandinavia’s largest online community for LGBT people, and via LGBT organization websites, social media, private e-mail contacts, Facebook groups, Google AdWords, and via information flyers at specialized gender clinics. The sample is hence self-selected, not randomized. The analysis included 796 respondents, which makes it the largest health survey among transgender people that has been conducted in Sweden to date. By the end of the data collection, 1205 individuals had participated. Of these, 77 were excluded since they did not fulfil the eligibility criteria; an additional 329 never submitted their responses after completing (some parts of) the survey and 3 were identified as duplicates.

The survey included 106 questions covering information on socio demographics, health, wellbeing, gender confirming treatment, living habits, experience of victimization and social contacts, sexual health and quality of life. The questionnaire was developed by a research team composed of researchers from the Karolinska Institute and from the Public Health Agency of 
Sweden as well as representatives from The Swedish Federation for LGBTQ Rights (RFSL) and The Youth Organisation for LGBTQ Rights (RFSL Ungdom). The average number of nonresponses for the sexual health questions was 17 out of 796 (2 \%), ranging from 1 to 30 .

\section{Web-survey respondents}

Individuals older than 15, who lived in Sweden, were Swedish speaking and who identified as being or having been transgender were eligible to participate. A majority of the respondents were born in Sweden (92\%) and lived in one of the three larger regional counties (65\%). More than half of the respondents were 15-29 years of age (53\%), one quarter was 30-44 years (25\%) and one fifth was above 44 years (16\% aged 45-64 and 5\% aged 65-94). Education level was high and a large majority had completed upper secondary education (50\%) or university education (29\%). The majority was studying or working (72\%) while 20 percent were unemployed or on sick-leave. Regarding transgender identity, respondents identified as gender non-binary (44\%), binary masculine (24\%), binary feminine (19\%) and transvestite (14\%). The majority had not changed their legal gender: 38 percent had not changed their legal gender but would like to; 26 percent said they had not and cannot change legal gender because it is not available in Sweden today; 20 percent had not and would not like to, while 14 percent responded yes, they had changed their legal gender. The respondents identified with many different sexual orientations and most commonly reported being bisexual (32\%) or queer (31\%) while approximately one fifth identified as heterosexual (19\%), lesbian or gay (18\%) or pansexual (22\%). Respondents could choose multiple responses on the question regarding sexual orientation and the frequencies described above, therefore, exceed a hundred percent. 


\section{The interview study}

An interview study with 20 informants on transgender peoples' experiences of sexual health was conducted in 2015 (Lindroth, 2016; Public Health Agency of Sweden, 2016). Experiences, and factors of importance for sexual health among transgender people in different ages, life phases and social circumstances were examined. Information about the study was spread through two non-governmental organizations: an organization whose members identify as transgender, Full Personality Expression Sweden (FPES), and through The Swedish Federation for LGBTQ Rights (RFSL). In addition, five key persons, active in sexual political organizations or working within gender confirming health care were asked to spread information of the study in their respective networks. People interested in participating were asked to contact the interviewer, via email or phone. Purposeful sampling was applied and inclusion criteria were to be 18 years or older, to have trans experience, and be willing to share thoughts on sexual health. Twenty interviews were conducted, and the informant chose the way to be interviewed; in a meeting $(n=12)$, over Skype $(n=6)$ over the phone $(n=1)$ and in writing $(n=1)$. The interviews had a narrative rather than interrogating character. The informants were asked to develop their thoughts on sexual health, specifically barriers and possibilities for sexual health. When 20 persons had been interviewed, a subjective assessment was made on saturation (Charmaz, 2010), as the results mirrored the informants' experiences well enough and data

collection ended. The interviews lasted between forty-five minutes and three and a half hour, on average one and a half hour and were analyzed with the use of constructivist Grounded Theory (Charmaz, 2010).

Interview study informants 
The informants were 18-75 years old, with an average age of 35 and a median age of 30 . The younger participants (aged 18-25, $n=5$ ) were often in the beginning, or in the middle of a gender identity assessment at a specialized clinic. Among the median aged informants (aged 26-40, $\mathrm{n}=9$ ) it had often, but not always, passed five to ten years since they were in gender-confirming care. Among the older informants (aged 41-75, $n=6$ ) some of the oldest were in the beginning of a gender-confirmatory process. Others had legally and medically transitioned nearly twenty years ago. Most were born and raised in Sweden, a few had another Nordic or central European background. A fourth lived in one of the three largest cities in Sweden, half in another city, and a fourth in a smaller city or rural area (less than 10000 inhabitants). Most informants had finished high school, and many had a university degree. Most worked or studied, a few received livelihood support due to mental ill health and yet another few were searching for an employment.

A great variety existed regarding informants' gender identity, and many said they used different terms in different situations: trans feminine, e.g. trans woman, trans girl, MtF, woman or girl ( $n=8)$, trans masculine, e.g. man, trans boy, FtM, man or boy $(n=7)$, and non-binary $(n=5)$. A few used the acronyms FtX (Female to X) or MtX (Male to X) about themselves and others, and explained that the $\mathrm{X}$ is inclusive towards all bodies, and individuals. Heterogeneity was also seen regarding sexual orientations. Most said they prefer sex with someone of the same gender, and many, those who identify as non-binary especially, said that the gender of a potential sex partner is irrelevant. Some preferred having a sex partner of the opposite sex.

\section{Analysis}

For the purpose of this paper, descriptive statistics (frequencies) from the web-based survey were combined with the results from the qualitative interview study (quotes) in order to provide an overall picture of sexual health among transgender people in Sweden. The result is divided 
in two sections. Physical, emotional and relational aspects of holistic sexual health, which presents numerical and narrative data on three different aspects of holistic sexual health. Next, numerical and narrative data on three potential sexual health determinants; Safer sex, access to testing and experiences of reimbursement for sex are presented. Figure 1. illustrates how the results from the two studies can be summarized in determinants of holistic sexual health, and includes physical, emotional and relational aspects that were identified in the interview study and corresponding quantitative indicators.

\section{Insert Figure 1 about here please}

\section{Results}

Physical, emotional and relational aspects of holistic sexual health

Findings from the web-based survey indicate that only 39 percent report that they can partly or fully live sexually as they would like to, while 32 percent respond they cannot, 23 percent are satisfied with their sex life and 35 percent are dissatisfied. In the interview study, it is shown that not being able to fully live sexually as one wishes, and being dissatisfied with one’s sex life have implications for the everyday (sexual) life and for sexual health, in different ways for different individuals. In the interview study, accounts of how bodies, emotions and relations are of importance for holistic sexual health are provided. The changing and sometimes changed physical bodies described by the informants are sometimes paused, and limits sexual practice. One of the informants who were awaiting a gender-confirming operation stated:

"My sexual health is bad right now. I try to compensate it by satisfying my partner. But, it works really bad actually, because there's not much in it for 
me. And hir knows that. So, we both long for my operation. I can't use my genitals today. The physical is preventing me."

For many, access to gender-confirming medical interventions (e.g. genital or chest reconstructive surgery and/or cross-sex hormone treatment) is described as vital component for their sexual health. Following gender confirming care, what can be described as a sexually active body is described as follows:

"I have a totally different sex life, and relation to my body now, yes, sexual health. It is, it's a struggle between the psychological and the physical somehow. But sometimes, it has been amazing. So, the possibilities are there, and I have become liberated because of the physical. The mental and the physical have connected somewhere, and what I, what I want with my sex life, it can suddenly happen."

For those who do not wish gender-confirming medical interventions acceptance of the body as it is, is stated as important. One participant says that there used to be a taboo around "a man with a pussy”, but he feels that times have changed, and refers to his genitals as:

"It works, why can't I use it, I enjoy it, what's wrong with that?"

Not only physical aspects, but also emotional appear essential to the holistic experience of sexual health, and also connected to access to care. Feelings of anxiety, uncertainty or fear in sexual situations hinders sexual health. Fear of, or experiences of, being met with disrespect are 
troubling, and sometimes this leads to an avoidance of flirting or trying to hook up with a potential sex partner:

"If the trans status hasn't been sorted out, the other one, the partner, might feel that he or she got tricked into something. And if you state it initially, that you are transgender, then there's the risk of the other backing out of the situation. So, it is difficult."

On the other hand, and as a contrast to problematic experiences, many describe feelings of happiness, courage and freedom related to sexuality. Some informants describe their trans experience as a source of strength, as a sexual asset:

“As a transgender person you have to reflect more. What do I like? What works for my body? There are a lot of prejudice, but you have to deal with it, and this can lead to that you become confident in your sexuality, and know what you want and what you don't want, what makes you feel good. One has to compromise in sexual practices, and we have moved away from how sex should be. I can focus on how I want to have sex."

Regarding the relational aspect of sexual health, 38 percent in the web-survey report they are in an ongoing sexual relationship with one partner; 14 percent with more than one partner; and 34 percent that they are not in a sexual relationship. Most informants in the interview study have an ongoing sexual relationship with one or more partners and a broader description of the relational aspect of sexual health is found. Relations (sexual or not) characterized with conflict or disrespect hinder, while functional and respectful relations (sexual or not) facilitate sexual health. More than half (51\%) of the respondents in the web-based survey report being exposed 
to offensive treatment at least once during the last three months. Having been exposed to offensive treatment due to ones gender expression (48 \%) is the most common reason reported (multiple choice), followed by gender (31\%), sexual identity (22\%), and appearance (15\%). In the interview study, experiences of being treated as a temporary sexual object, as an arousing fetish, or as a sex toy not as a person, by mainly heterosexual men occur. Overall, many talk of how women are more open-minded in general towards transgender people, and one man who identifies as gay says:

"The girls I've met, they have been more accepting. But every time I've tried to find a boyfriend, it has been, well there's all kinds of trouble. Homosexual men, the gays, they are really "Ooops, you used to be a woman, oops" and then they run away. And I've grown so tired of it, there is a lack of knowledge within the gay community as well. Give me a chance to explain, to show who I am. Not just how I look, or work sexually, I am a human being. But, it's black or white. And sure, some have been curious, had some fun experimenting, but then they run away. I've felt so much discrimination. A lot of preconceptions, prejudice, fear and lack of knowledge."

Offensive treatment does not only take place when trying to find a sexual partner. Experiences of being treated offensively within specialized transgender care is also shared. An informant assigned male at birth share experiences of heteronormative assumptions:

"The comment from my counsellor says it all, the counsellor asked me:

"Well, but if you don't fancy men, then why do you want a pussy?"” 
Relations, intimate or formal, that are respectful and where one gets validation for who one is appears vital for sexual health. Not being objectified, discriminated against or sexually abused is essential. Experiences of being in a respectful relation and its positive effect on sexual health are also common. As one example of this one of the informants says they have just recently met the perfect partner:

"And he tells me: You are who you are, and I love you just the way you are, no problems. So, I feel safe with him, I can be who I am."

In the web survey, one third (30\%) report they have been forced to have sex against their own will at some point in time. Approximately one third of respondents reporting sexual coercion (multiple choice) said they were forced by a partner (32\%); one fourth by an unknown person (27\%); one fourth by someone they knew (28\%); and one fifth by a friend (21\%). In the interview study, sex against one's will is being described along what can be seen as a continuum, with rape and sex that one regrets in the respective ends. The term "validation sex" is mentioned, and that this may be common regardless if an individual is transgender or not, but that the trans experience can add a certain vulnerability leading to sex that one later regrets:

"If you are born in, or feel that you were born in a body that you're not comfortable in, it can become very destructive, regarding sexuality, sexual practises that is. I think there are bigger, both physical and psychological problems, problems that have been present for a large part of your life. You disparage yourself. You are born in a body that you want to change, that you are not comfortable with. You don't like, you don't love yourself." 
Experiences of safer sex, access to testing, and of reimbursement for sex

The most common answer to the web-survey question on condom use when having vaginal or anal intercourse was that condom is not needed for the type of sex one is having. This answer was given by 42 percent among respondents, who were in an ongoing sexual relationship with one partner and among 35 percent among respondents involved in an ongoing sexual relationship with more than one partner. Always using a condom is more common among respondents with more than one ongoing sexual relationship (22\%) compared to respondents with one ongoing sexual relationship (11\%). In line with this, many of the informants in the interview study refer to the practice of safer sex, to having same sex practices with a minimal risk of STI transmission, to being in monogamous relationships or to not having sex at all at the moment. However, safer sex practices are not always applied, and some recall earlier periods in life where sexual risk taking occurred, with STI testing as a part of that period:

\section{"I took what I could get, and it was always, always under the influence of alcohol, in gay bars. I wasn't proud of it, but it satisfied a certain need. And afterwards, you were ashamed of yourself, and had to take tests”.}

A majority of respondents in the web-survey say they have received sufficient information in order to protect one self and one’s partner from HIV (83\%) and other STIs (75\%). At the same time, 37 percent report not knowing where one can be treated with respect while getting tested for HIV or other STIs. Forty-six percent of the respondents have never had an HIV test. A large proportion report they have abstained from seeking general health care; 23 percent due to previous negative experiences of being treated with disrespect and 40 percent due to fear of being treated offensively. In the interview study as well, experiences of disrespectful treatment 
within a variety of health care settings (e.g. gender identity assessment clinics, youth clinics, mental health clinics, STI clinics) are common. The informants describe what is interpreted as an overall wish for equal access to sexual health care, or as one of them says:

\author{
"What's missing is all that concerns everyday health, like getting tested and \\ how to get hold of a good gynecologist? How can you get it all, and not only \\ all that is considered exotic about transgender, but all the other stuff that all \\ people need?”
}

In the web-survey 10 percent say they have experiences of receiving reimbursement for sex: 3 percent had done it once and 7 percent had done it several times. Various reasons are given (multiple choice): due to lack of income and need of money (41\%); because it was exciting (25\%); to self-harm (24\%); to receive validation in relation to gender identity (19\%); and not being able to resist the reimbursement that was offered (19\%). When transactional sex is discussed in the interview study, none of the informants share experiences of this. Many point out that the context, mainly access to affordable gender-confirmatory care, may have a preventive effect:

"I'd say it's more common in other countries, where you don't have access to state funded care. Then you have to get the money somewhere else, hence prostitution, because you have such a low status and can't get a job.”

\title{
Insert Table 1. about here please
}

\section{Discussion}

The twofold purpose of this paper was to explore and describe sexual health among transgender people in Sweden and also to illuminate experiences of safer sex, access to testing and 
reimbursement for sex. The combined results depict consistent and similar findings that provide nuance to the findings from the different studies. The results underline previous transgender research on the mechanisms behind discrimination and stigma and the negative impact on health. It also illuminates an area not well studied in transgender research: holistic sexual health. Physical, emotional and relational well-being are all vital aspects for experiencing sexual health, i.e. they are all important sexual health determinants, although of different importance to different individuals in different times.

The combined results in this paper also indicate that safer sex practices are common, and that exposure to HIV and other STIs may be low. Still, the results point out that safer sex practices might be abandoned in times of mental ill-health, and risk taking increased. It is worrisome that more than a third of the web-survey respondents say they lack access to STI/HIV testing that includes being treated in a respectful way. These figures indicate a lack of equitable sexual health services. This may have an impact on an individual's propensity to use testing services and on estimates of STI/HIV prevalence in this group. The numbers are in line with findings from a comparative study including 6, 579 transgender participants from 28 European countries, were more than half stated that they had been discriminated against during the last year, and one in five that this discrimination had taken place within a health or social care setting (European Union Agency for Fundamental Rights, 2014). The findings are also supported by what transgender people in Sweden have experienced in meetings with professionals in different sexual health promoting settings (Lindroth, 2016). They experienced being discriminated by professionals due to who they are. This discrimination appears connected to hetero- and cis normative as well as gender binary expectations from professionals. Feelings of being evicted from the health care system as soon as gender-confirming care was over, i.e. limited support to function in a new sexual role, were also expressed. In addition, a lack of access to different forms of sexual health screenings (e.g. pap-smear, prostate screening) were 
voiced (Lindroth, 2016). Regarding discrimination due to sexual orientation or preference, professionals must focus on sexual preferences and experiences, not on what sexual identity or orientation category the person is supposed to fit into (van Anders, 2015). This may liberate sexual minorities and the assumption that sexuality or sexual identity automatically equals or has its departure point in gender (trans, non-binary or cis) or preference (bi, homo or hetero) can be avoided (van Anders, 2015).

The proportion with experience of reimbursement for sex at some point in time in the websurvey (10\%) was higher than in other Swedish findings, indicating that 0,4-1,2 percent among adults (County Administrative Board Stockholm, 2015) and 2,5 percent of adolescents and young adults aged 15-29 years have experience of transactional sex (Public Health Agency of Sweden, forthcoming). However, due to differences in methodology, comparisons cannot be made. As mentioned by the informants in the present study, access to affordable or state funded gender-confirming care may prevent transgender people in Sweden from selling sex to finance clinical care and treatment. Still, non-prejudice attention needs to be provided to transgender people who do engage in transactional sex. Their sexual health may otherwise be jeopardized as they risk being met with the double stigma of being transgender and a sex worker (World Health Organization, 2015).

The results as a whole demonstrate a heterogeneity among transgender people, which calls for individualized treatment and care in order to promote sexual health. This has also been recognized in the 2015 recommendations for specialized care of adults with gender dysphoria in Sweden. These national guidelines stress that individualized sexological and sexual medical counselling and treatment should be offered within the health care system (National Board of Health and Welfare, 2015). When describing future research concerning transgender people, a focus on treatments and interventions that tackle exposure to discrimination, and on resilience as well as heterogeneity has been suggested (Bouman, de Vries \& T'Sjoen, 2016; MacCarthy 
et al., 2014). The current paper indicates that the same applies to transgender people and sexual health, future research, and clinical practice, should focus on individualized, nondiscriminatory and accessible sexual health promotion and care.

The paper has several limitations. For instance, both samples are very homogenous regarding ethnicity and individuals not speaking Swedish fluently were probably less likely to participate. How treatment due to racial prejudice interacts with sexual health among transgender people is not seen in the results. Moreover, reproductive health is not discussed, even though it is a major aspect of sexual health. In addition, the interview study only reached informants who identified as transgender and non-binary, experiences among individuals who identify as transvestites, drag-Queens and drag-Kings are lacking. The web-based survey was a convenience sample, which limits the generalizability to the transgender group. However, online surveys are an important tool in research regarding hard to reach groups and a strength of the paper is that it presents a large and in many other respects heterogeneous sample of transgender and nonbinary people. The setting should also be acknowledged. Sweden has, compared to many other countries, a progressive health care system that acknowledges the rights of transgender people, and a legislation on selling or buying sex that might have had an impact on the results. This puts a limitation on the possibility to generalize the findings. To our knowledge this is, however the first paper exploring and describing holistic sexual health and experiences of safer sex, access to testing and reimbursement for sex among transgender people, combining numerical and narrative data. As such it is assumed, despite the lack of generalizability, to be of interest to sexual health researchers as well as to clinicians in a variety of sexual health promoting settings. 


\section{Implications}

The main theme in the results is that transgender peoples' sexual health is largely affected by events out of their direct control. Access to non-discriminatory gender-confirming care as well as sexual health care, access to non-discriminatory testing facilities and a non-discriminatory overall treatment in society is needed. For holistic sexual health to be strengthened and sexual rights (the possibility of having pleasurable and safe sexual experiences free of coercion, discrimination and violence) respected in this group, continuous efforts to increase knowledge and educate in society as a whole, but also in specific health care settings are paramount. The findings in the present paper can be seen as one piece of knowledge to be used in this vital public health - and sexual health - enterprise.

\section{References}

Adams, K.A., Nagoshi, C.T., Filip-Crawford, G., Terrell, H.K., \& Nagoshi, J.L. (2016).

Components of gender-nonconformity prejudice. International Journal of Transgenderism, 17(3+4), 185-198.

Baral, S.D., Poteat, T., Stromdahl, S., Wirtz, A.L., Guadamuz, T.E., \& Beyrer, C. (2013).

Worldwide burden of HIV in transgender women: a systematic review and meta-analysis. The Lancet Infectious Diseases, 13(3), 214-222.

Bauer, G.R., Scheim, A.I., Pyne, J., Travers, R., \& Hammond, R. (2015). Intervenable factors associated with suicide risk in transgender persons: a respondent driven sampling study in Ontario, Canada. BMC Public Health, 15, 525.

Bouman, W.P., de Vries, A.L.C. \& T’Sjoen, G. (2016). Gender dysphoria and gender incongruence: An evolving inter-disciplinary field. International Review of Psychiatry, 28(1), $1-4$. 
Charmaz, K. (2010). Constructing Grounded Theory: a practical guide through qualitative analysis. London: SAGE Publications.

Costantino, A., Cerpolini, S., Alvisi,S., Morselli,PG., Venturoli, S. \& Meriggiola, MC. (2013). A prospective study on sexual function and mood in Female-to-Male transsexuals during testosterone administration and after sex reassignment surgery. Journal of Sex \& Marital Therapy, 39(4), 321-335.

County Administrative Board Stockholm (2015). The extent and development of prostitution in Sweden 2014. Stockholm: County Administrative Board Stockholm. In Swedish, English summary available at:

http://www.lansstyrelsen.se/Stockholm/Sv/nyheter/2015/Pages/prostitutionen-i-sverige-2014en-omfattningskartlaggning.aspx

Dhejne, C., Lichtenstein, P., Boman, M., Johansson, A.L.V., Långström, N., \& Landén, M. (2011). Long-Term Follow-Up of Transsexual Persons Undergoing Sex Reassignment Surgery: Cohort Study in Sweden. PLoS ONE 6(2), e16885

Dhejne, C, Öberg, K, Arver, S., \& Landén, M. (2014). An analysis of all applications for sex reassignment surgery in Sweden, 1960-2010: Prevalence, incidence and regrets. Archives of Sexual Behaviour, 43, 1535-1545.

Dhejne, C., Van Vlerken, R., Heylens, G., \& Arcelus, J. (2016). Mental health and gender dysphoria: A review of the literature. International Review of Psychiatry, 28(1), 44-47. 
European Union Agency for Fundamental Rights (2014). Being Trans in the EU Comparative analysis of EU LGBT survey data. Luxembourg: Publications Office of the European Union; 2014. Available at: http://fra.europa.eu/en/publication/2014/being-trans-eucomparative-analysis-eu-lgbt-survey-data

Government Offices of Sweden. (2015). A strategy for equal rights and opportunities regardless of sexual orientation, transgender identity or expression. English version available at: http://www.government.se/articles/2015/05/a-strategy-for-equal-rights-andopportunities-regardless-of-sexual-orientation-gender-identity-or-gender-expression/

Gäredal, M. \& Orre, C. (2011). Safe contexts makes me horny. A study on transgender people's experiences and thoughts on sex and the need of knowledge and actions regarding sexual health. Stockholm: Swedish Federation for LGBTQ Rights \& Swedish Youth Organisation for LGBTQ Rights. (2010). In Swedish, English summary available at: http://rfslungdom.se/webbshop/trygga-sammanhang-gor-mig-kat

Kanamori, Y., \& Cornelius-White, J.H.D. (2016). Big changes, but are they big enough? Healthcare professionals' attitudes toward transgender persons. International Journal of Transgenderism, 17 (3+4), 165-175.

Kattari, S. K., Walls, N. E., Whitfield, D. L., \& Langenderfer-Magruder, L. (2015). Racial and ethnic differences in experiences of discrimination in accessing health services among transgender people in the United States. International Journal of Transgenderism, 16, 68-79. 
Leppel, K. (2016). The labor force ftatus of transgender men and women. International Journal of Transgenderism, 17 (3+4), 155-164.

Lindroth, M. (2016). "Competent persons who can treat you with competence, as simple as that" - An interview study with transgender people on their experiences of meeting health care professionals. Journal of Clinical Nursing, 25(23-24), 3511-3521.

Lombardi, E. (2001). Enhancing transgender health care. American Journal of Public Health, 91, 869-872.

MacCarthy, S., Reisner, S., Nunn, A., Perez-Brumer, A., \& Operario, D. (2015). The time is now: Attention increases to transgender health in the United States but scientific gaps remains. LGBT Health, 2(4), 287-291 .

Meyer, I.H. (2007). Prejudice and discrimination as social stressors. In: I.H. Meyer \& M.E Northridge (Eds.). The health of sexual minorities, pp 242-267. New York: Springer.

Millet, N., Longworth, J., \& Arcelus, J. (2017). Prevalence of anxiety symptoms and disorders in the Transgender population: A systematic review of the literature. International Journal of Transgenderism, 18(1), 27-38.

Motmans, J., Meier, P., Ponnet, K. \& T’Sjoen,G. (2012). Female and male transgender Quality of Life: Socioeconomic and medical differences. Journal of Sexual Medicine, 9 (3), 743-750. 
National Board of Health and Welfare. (2015). Recommendations for specialized care of adults with gender dysphoria in Sweden. Stockholm: Board of Health and Welfare. In Swedish, English summary available at:

http://www.socialstyrelsen.se/publikationer2015/2015-4-7

Pitts, M.K., Couch, M., Mulcare, H., Croy, S. \& Mitchell, A. (2009). Transgender people in Australia and New Zealand: Health, well-being and access to health services. Feminism \& Psychology, 19(4), 475-495.

Public Health Agency of Sweden. (forthcoming). Health and sexuality among young people and young adults 16-29 years in Sweden. Stockholm: Public Health Agency of Sweden.

Public Health Agency of Sweden. (2015a). The National Public Health Survey 2015.

(Charlotte Deogan, personal communication, November 24, 2016).

Public Health Agency of Sweden. (2015b). Health and health determinants among transgender persons - a report on the health status of transgender persons in Sweden. Stockholm: Public Health Agency. In Swedish, English summary available at: https://www.folkhalsomyndigheten.se/pagefiles/20250/halsan-halsans-bestamningsfaktorertranspersoner-15038-webb.pdf

Public Health Agency of Sweden. (2016). The right to health - how norms and structures affect transgender people's experiences of sexual health. Stockholm: Public Health Agency of Sweden. In Swedish, English summary available at: 
https://www.folkhalsomyndigheten.se/publicerat-material/publikationer/Ratten-till-halsa--hurnormer-och-strukturer-inverkar-pa-transpersoners-upplevelser-av-sexuell-halsa/

Roller, C.G., Sedlak, C. \& Draucker, C.B. (2015), Navigating the system: How transgender individuals engage in health care services. Journal of Nursing Scholarship, 47, 417-424.

Reisner, S.L, Poteat, T., Keatley, J., Cabral, M., Mothopeng, T., Dunham, E., Holland, C.E., Max, R., \& Baral, S.D. (2016). Global health burden and needs of transgender populations: a review. Lancet, 388(10042), 412-36.

The Lancet Series (2016). Transgender Health Executive Summary June 17 2016. Available at: http://www.thelancet.com/series/transgender-health

van Anders, S. (2015). Beyond sexual orientation: Integrating gender/sex and diverse sexualities via sexual configurations theory. Archives of Sexual Behavior, 44(5), 1177-1213.

Wierckx, K., Van Caenegem, E., Elaut, E., Dedecker, D., Van de Peer, F., Tove, K., Weyers, S., Hoebe, P., De Cuypere, G. \& T'Sjoen, G. (2011) Quality of life and sexual health after sex reassignment surgery in transsexual men. Journal of Sexual Medicine, 8(12), 3379-88.

Weyers,S., Elaut, E., De Sutter, P., Gerris, J., T’Sjoen, G., Heylens, G., De Cuypere, G. \& Verstraelen, H. (2009). Long-term assessment of the physical, mental, and sexual health among transsexual women. Journal of Sexual Medicine, 6(3), 752-760. 
World Health Organization. (2015). Sexual health, human rights and the law. Geneva: WHO Document Production Services.

Zeluf, G., Dhejne, C., Orre, C., Nilunger Mannheimer, L. Deogan, C., Höijer, J., \& Ekéus Thorson, A. (2016). Health, disability and quality of life among trans people in Sweden-a web-based survey. BMC Public Health, 16, 903. 